
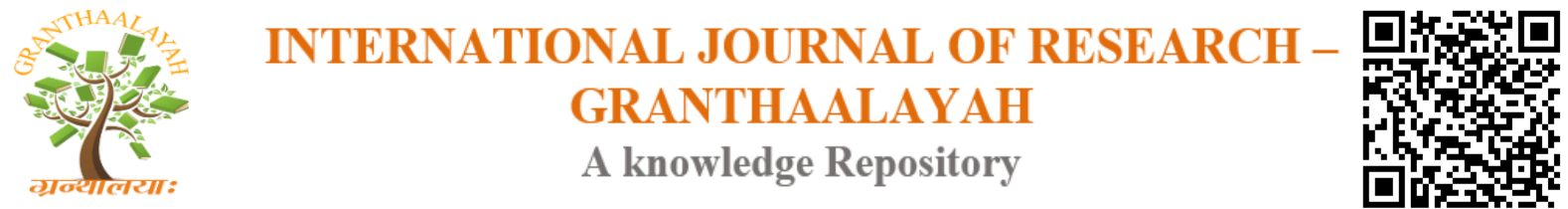

Management

\title{
INNOVATIVE PROJECT MANAGEMENT METHODOLOGY FOR GLOBAL EDUCATIONAL MARKET
}

\author{
Alexander S. Ryzhkov *1 \\ ${ }^{* 1}$ Heroyiv Ukrainy Ave., 9, Mykolaiv, Ukraine, 54025
}

\begin{abstract}
Innovative project management methodology for the provision of educational services to the foreign customer was developed. In this methodology is applied the general calculation of a quantitative assessment of the quality of teaching. To significantly reduce the time for calculations, the universal computing program has been created, which allows to process extensive data blocks with the visualization of the results in the two-dimensional coordinate system. This methodology was implemented to working process of Admiral Makarov National University of Shipbuilding. The results made it possible to quickly make adjustments in the educational process in order to improve the quality of educational services for the international customer.
\end{abstract}

Keywords: PME; UCP; Sectoral Distribution of Responsibility; The Fundamental Approaches of Project Management; International Educational Program.

Cite This Article: Alexander S. Ryzhkov. (2017). "INNOVATIVE PROJECT MANAGEMENT METHODOLOGY FOR GLOBAL EDUCATIONAL MARKET." International Journal of Research - Granthaalayah, 5(9), 171-185. 10.29121/granthaalayah.v5.19.2017.2227.

\section{Introduction}

The formation of Ukraine as an integral partner of the European Union and serious player in the global arena is impossible without strong integration of not only economic factors, but cultural and educational components.

The Association Agreement between Ukraine and the European Union signed on June 27, 2014, includes the process of implementation of European standards into many areas of life activity and healthy operation of a State. In particular, this concerns also the educational process. Everyone knows the high standards of the West in the educational field which means the increase of the Ukrainian education level.

The globalization of the educational services market causes the transformation of national education systems of many countries. As a strongly marked indicator of this phenomenon there can be such countries as the USA, the UK, South Korea, Eastern Europe countries, etc. For 
Ukraine, as for other European countries, except from the system reforms, the most important factor of higher education reformation is the introduction and development of the Bologna process as a consequence of globalization [1].

On June 19, 1999, 29 European Ministers of Education signed the Bologna Declaration [2] which became the catalyst of the development and modification of the Sorbonne Declaration ideas [3] on the European Higher Education Area. It promotes closer contacts between European countries in the development and strengthening of intellectual, social, scientific and technological potentials, academic and general cultural enrichment.

The academic mobility of students, a wide degree of autonomy in decision-making and active international activity are the most important components of the successful life activity of European universities. Considering the European model of education, we should take into account a factor of competitive activity. The educational services of the West are connected to the market economy and act according to the simple and hard "supply and demand" law. The specialty which is not interesting for the market employment cannot compete and the university has to cut it with all its consequences (redundancy, decrease of study load, etc.). In fact, the ability of Western universities to adapt to the constant changes of our time is the key to a successful operation.

Accepting the European standards, the Ukrainian higher educational establishments should be aware that they accept also the conditions of healthy competition not only between each other, but also between the European universities. And if the universities in the UK, France and Germany has a little interest for the majority of Ukrainian applicants because of the historically formed circumstances of pricing and other factors, then the universities of such countries as Poland, Slovakia and the Czech Republic look more attractive and real. The general level of satisfaction with the education system in these countries is higher than in Ukraine, as the "Report on Human Development over 2013" data evidences [4].

In conditions of the increasing competition in the global education area, the correspondence to high criteria and international standards is the only way of functioning of the higher educational establishment in Ukraine. And this cannot be achieved without the active international activity which is aimed at the development of international educational programs.

Heading for the international integration, we should remember about the needs of Ukrainian regions on which the university works. Currently, there is uncoordinated work between the higher education and potential employers in conditions of development of market relations and the labor market. In the industrial regions of Ukraine it is primarily connected with the active modernization of industrial enterprises: purchase of modern high-tech equipment, usage of the latest software, expansion of the range of products. It leads to the need for constant updating of training programs for junior specialists in accordance with the realities of regional labor market. [5]

To achieve these aims, the management of higher educational establishment should be a balanced mix of professional managers, specialists on project management, supervisors and teachers which can flexibly and effectively react to any circumstances of modernity. 
The "Creation of a University of the European Type" program has been still fulfilling at the Admiral Makarov National University of Shipbuilding (NUS) since 2008 as a part of the "Concept of the NUS Development"[6]. The concepts and fulfillment of international educational programs of this university are used as the basis of this study.

\section{Analysis of Recent Achievements}

Project Quality Management includes all activities that relate to general management functions, determine the quality policy, objectives and responsibilities and implement them by such means as quality planning, its control and improvement within the quality assurance $[7,8,9]$.

The process of quality management project has three main components: quality planning, quality assurance and quality control. Those methods to control the quality of the high school teachers make it difficult to perform correct quantitative assessment. The need for this assessment indicates a large number of researcher, linking measures to motivate teachers for quality labor with the ability of the administration to have an correct assessment of teachers work [10-14].

At NUS it is used to consider teacher as a person who seeks to help the student to learn the necessary knowledge and skills required by educational standards. Based on this consideration the calculation to quantify the quality of teaching is taken as a standard [15,16,17]. This calculation is used for the evaluation of the educational process for Ukraine, but for assessing the implementation of international educational programs it is applied first time. In literature no data on the existence of an universal computing program for calculation of a quantitative assessment of the quality of teaching. Therefore, to simplify the calculations to quantify the quality of education has been developed the computing program.

The international activity and cooperation with foreign organizations was carried out according to the "Concept of the NUS Development" and "Tasks of the National University of Shipbuilding, the vector of the development remains unchanged [18].

The object of the study is an international educational programs of NUS, and the subject is the successful functioning of the mechanisms and the implementation of these programs.

The Scientific Educational Centre of International Cooperation has effectively performed the activity on attracting the foreign citizens to study at the NUS. Thus, from 2011 to 2016 there is a record tendency on the increase of foreign students, postgraduates and trainees who want to improve their skills over the entire period of the university existence. Thus, as at the beginning of 2008 there were only 88 foreign students at the NUS. As at the beginning of February, 2016, 1073 foreign citizens from 24 countries studied at the NUS. The number of foreigners at the NUS has increased in more than 13 times which is a high indicator of the dynamics of the international cooperation development (fig 1). 


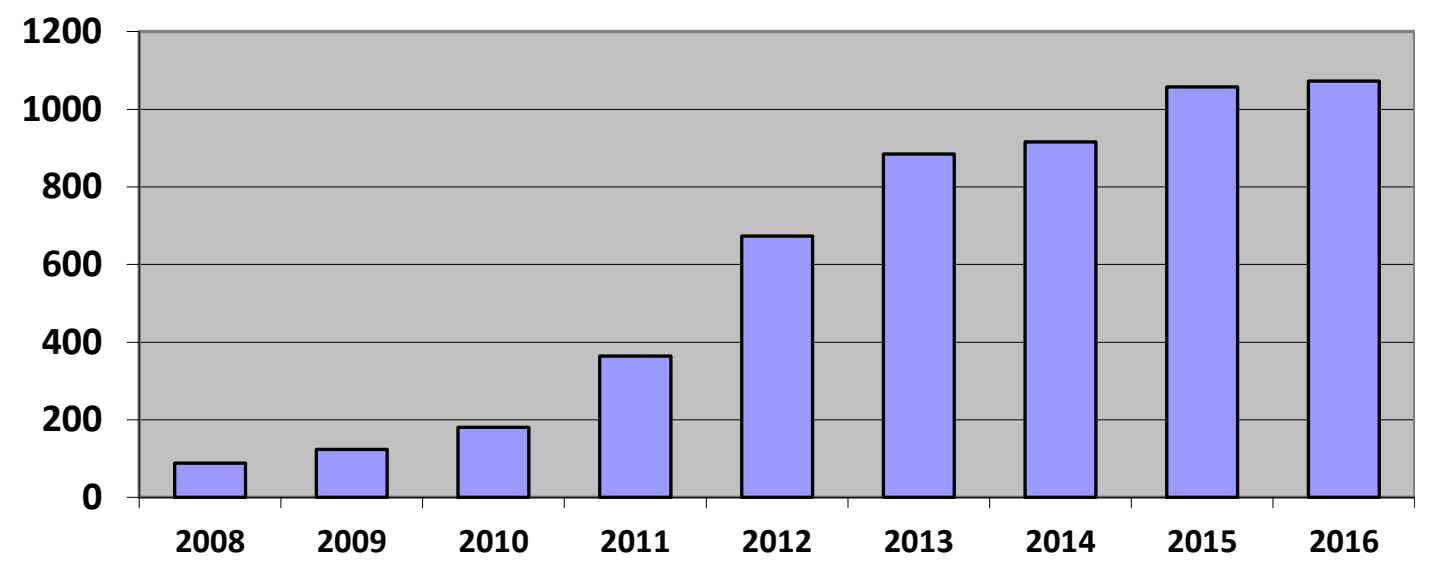

Figure 1: Number of foreign students in NUS

A training program is developing at the NUS with the International Maritime College (Zhejiang International Maritime College), Zhoushan, China. Over four years 70 Chinese graduates (junior specialists) of the college were directed in order to obtain the higher technical education (Bachelor degree) in the "Marine Engineering" knowledge field (Specialty "Ships and Ocean Engineering", "SPP") on the " $2+2$ " program. In summer 2013 the first graduation of Bachelors in this program (13 people) was held and in summer 2014 the second one (14 people) was also held. $30 \%$ of graduates continue their education in a Master's program. In 2015 - 17 people. In 2016 new group of 22 students have graduated.

The agreement with the management of the Jiangsu University of Science and Technology, China, is fulfilled on the co-operative Bachelors' training in the "Ships and Ocean Engineering" direction on the " $4+0$ " program. There were 181 students over 2012-2015. Currently there is a campaign to enroll the fifth group.

In 2012 the agreement was signed on the Partnership and Cooperation between the Admiral Makarov National University of Shipbuilding, Mykolayiv, Ukraine and Batumi Navigational Teaching University, Batumi, Georgia. Within the cooperation the educational counseling NUS center in Batumi was opened on the basis of the BNTU to fulfill the training of students on the Bachelor programs. 217 students were enrolled on the training in various specialties. Currently there is a new admission campaign.

The negotiations have been continued and the preliminary agreements on the forms of cooperation in the direction of the Specialists' training with the government agencies and universities of Poland, Norway, Belgium, Turkey, Azerbaijan, Tajikistan, Georgia, Turkmenistan, China, Estonia, Argentina, etc. have been reached.

\section{Presentation of the Base Material}

Accumulated many years of NUS experience with international customers makes it possible for a rational approach creation for the project management of the foreign segment. Existing management models do not fully meet their stated objectives for the implementation of these projects. In particular, the closest models: traditional (cascade) project management methodology 
is not suitable because of its inertness and intolerance to changes, and popular in the west methodology PRINCE2 would make a lot of additional bureaucratic claims [7].

Based on the results of the project management performed by Educational Scientific Centre of International Cooperation of NUS the project management methodology to provide the educational services to the foreign customer has been developed (Project Management for Education, PME). The processes of PME-methodology are shown in Figure 2.

The principles of the PME-methodology:

1) Possibility Assessment, selection of performers - whether the university is able to complete an international project in accordance with the requirements of the customer, in the case of a positive assessment the necessary university structural units are picked and the team of project executors is being formed.

2) The continuous growth - to take into account the wishes of the customer, to accumulate experience.

3) The use of the mechanism of "shared responsibility" - the responsibility for a positive outcome of the project is not only the main executor headache (in common, the international structural unit of the university is the main executor), but also it is a responsibility of all other structural units that are involved in the project.

4) Evaluation of the quality of work - maintaining an unprejudiced control over the quality of educational services provided by the university. The constant desire to improve and meet the high international standards.

5) Sectoral project management - project is divided into blocks (sectors), every sector has its executing team.

Aspects of the PME-methodology:

1) Planning - preparation for implementation of the project, verification of curricula, preparation of supporting documents, dispatching support.

2) Co-ordination - the allocation of responsibilities, the matching of structural divisions.

3) Execution - the level of compliance of planned results to the actual implementation.

4) Risks - mechanisms to solve possible contingencies in the planning and the factors of external interference.

The processes of PME-methodology:

1) Rector's control.

2) Rector, or its authorized person conducts supervision over the implementation of the University obligations to the international customer. It is implemented throughout the project period.

3) Start of the project.

4) The reason for the start of the project is the international contract for the provision of educational services. It is also the plan of the project. At this stage of the project the responsible executors are appointed and all preparatory work is carried out.

5) Project Management.

This stage is characterized by the distribution of sectoral responsibility.

6) Implementation of the project. 
The fundamental stage of the project, which is a direct provision of educational services to international students/trainees by basic university divisions - departments.

7) Monitoring of progress.

At the expiration of the specified time period, a comprehensive monitoring of the implementation of the project to identify abnormalities and other negative factors that can hinder the implementation of the contract is being performed. Usually selected time period is an educational semester.

8) Quality of teaching monitoring.

Implemented together with the control performance and is aimed at compliance with international teaching criteria.

9) Completion of the project.

It is characterized by the implementation of terms and conditions of the contract with the issuance of diplomas/certificates to foreign citizens who have completed all requirements for the assignment of corresponding qualification.

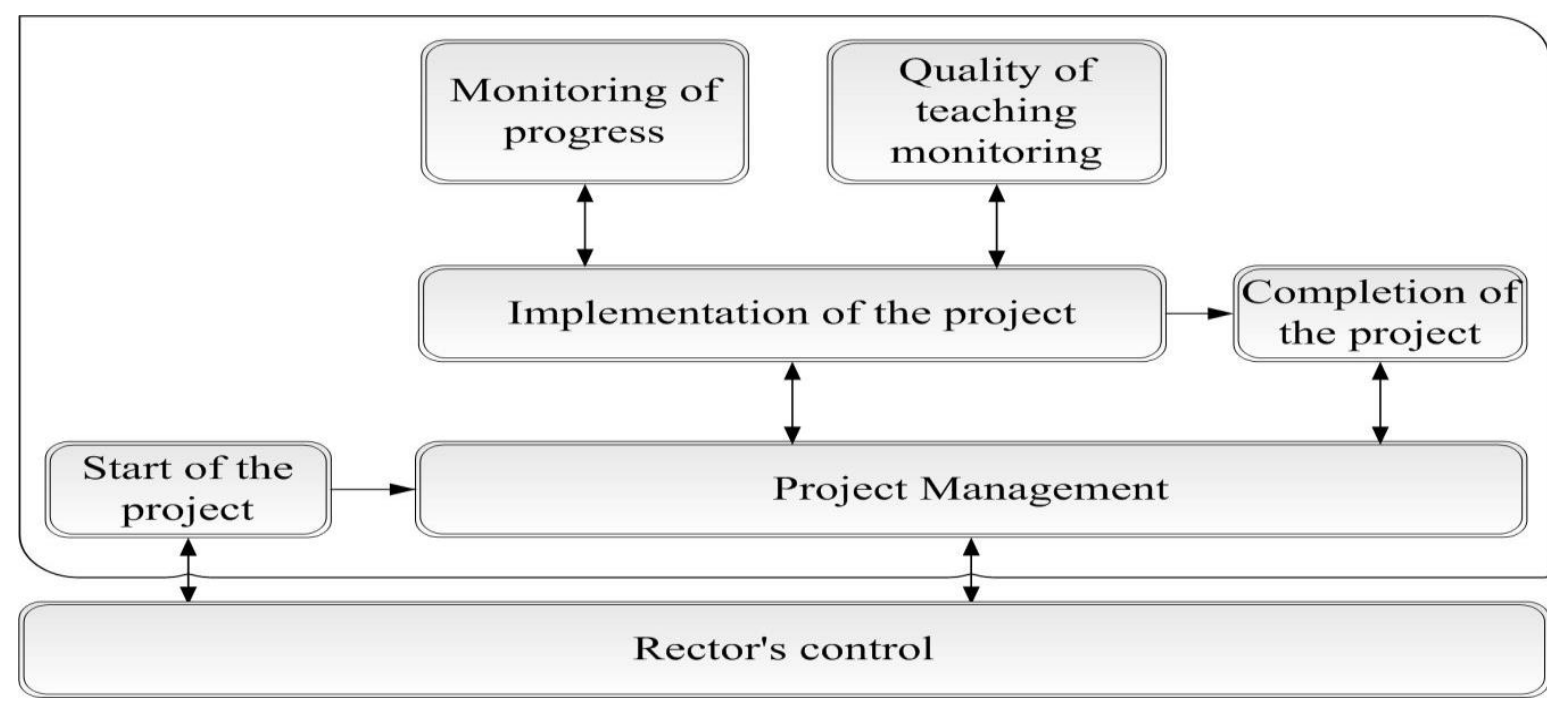

Figure 2: The processes of project management methods to provide educational services to the foreign customer

\section{Results and Discussions}

As an example lets study two main educational programs performed by NUS for foreign partners [6].

The "2+2" Program.

Specialty: "Ships and Ocean Engineering".

Teaching language: English.

Partner: Zhejiang International Maritime College, China (ZIMC).

Year of agreement signing: 2010.

Study duration: 2 years in China, 2 years in Ukraine.

1st graduation: June 2013.

The main point of this program is to train the students for a bachelor degree on the basis of twoyear training in China followed by the study continuation in Ukraine. A state-pattern diploma of Ukraine is the final result. 
This is a complex project which is included in the concept of the general NUS program of formation of a University of the European type. In this context, the fulfillment of training potential in the international arena is understood.

A group of students is the input data for this project. The final aim of the project is gained when these students obtain a Bachelor's diploma. The Educational Scientific Center of International Cooperation in Ukraine and the International ZIMC office in China manage this project. The International Relations and Learning and Teaching sectors distribute the duties upon program functioning at the NUS. The success of this project can only be achieved under the close cooperation and collaboration with other university departments, mostly with the Shipbuilding Institute and its leading departments and it resembles a coherent clockwork mechanism in which everything stops in case of a unit failure.

As is shown in Figure 3, each structural subdivision which is involved in the program is responsible for specific tasks which allow successful carrying out of the project. There have already been completed two projects by July 2014: two groups graduated with Bachelor's diplomas, the total number of graduates is 27 people. In 2015, there are plans to graduate 17 new young specialists. The study continuation of some graduates on the Master's Program is a positive complementary product of this program. It should be noted, that the Master's program is carried out in Russian, so the attention is paid to the Russian language course during two years of study in English.

Basing on the experience of successful fulfillments, it should be noted, that the " $2+2$ " project is subjected to a number of problems despite the visible rational distribution of responsibilities. All the problems are based on such a concept as a "human factor". It shows itself both by the students and by the methodologists, specialists and teachers. It gets also worse by the fact that a fairly low percentage of teachers knows English sufficiently to conduct lectures and practical activities in English, despite the large number of highly qualified personnel at the NUS. This is a slowing component under the integration into the global educational process and one should work seriously on this issue.

One teacher teaches several disciplines and when he/she can not be in the class for some reasons, nobody can replace him/her. In this case, the ESCIC learning and teaching sector controls the situation. It reschedules classes for the days which are more comfortable for the teacher who missed the classes. This, in its turn, can cause other teachers' dissatisfaction, whose schedule changes as a consequence.

The solution of conflicts and minimization of harm by means of the human factor are one of the most important roles in the project of the Educational Scientific Center of International Cooperation. 


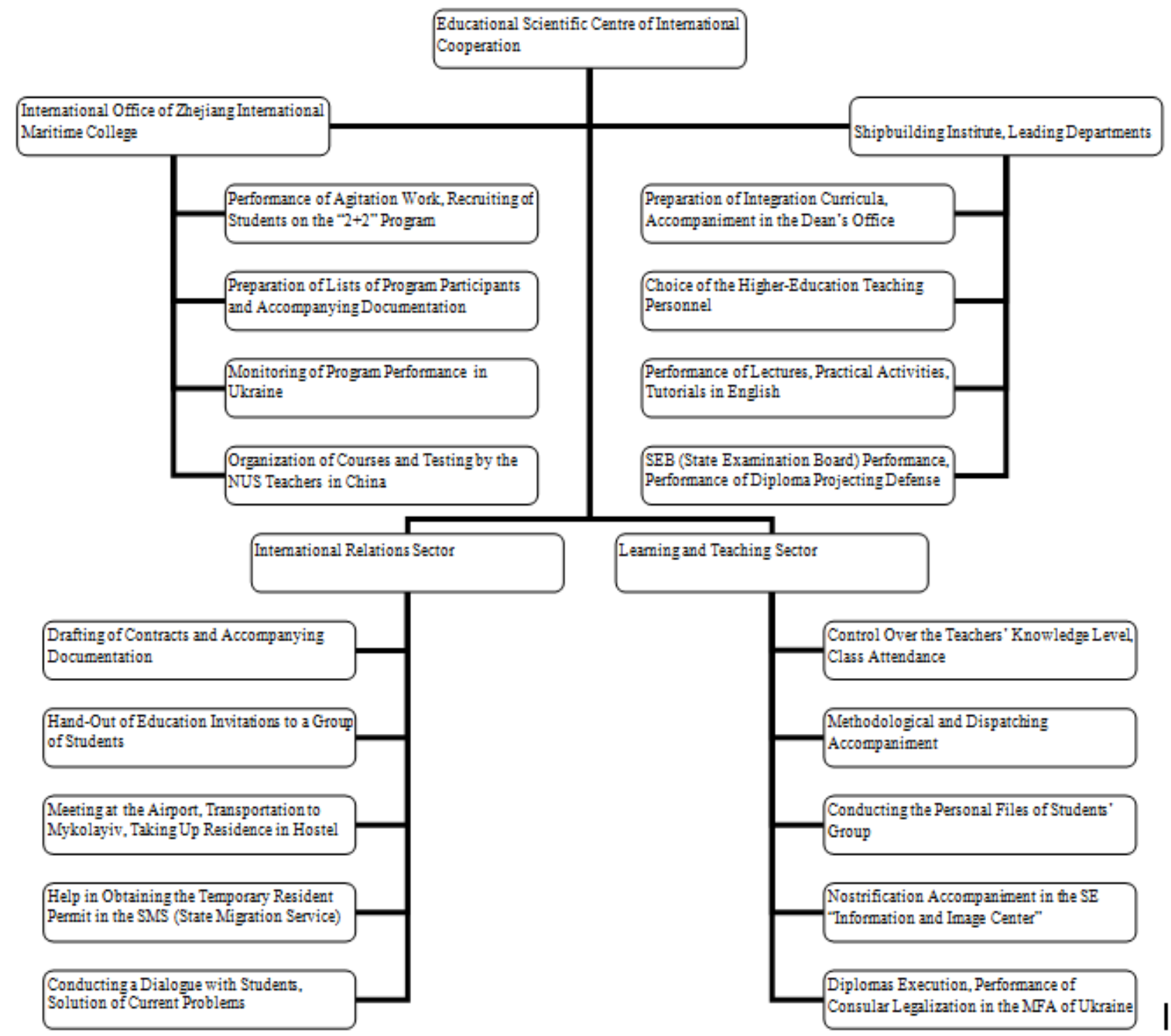

Figure 3: Sectoral Responsibility Distribution under the Project Management of the " $2+2$ " Training Program

Only the well-coordinated work of structural subdivisions reinforced by a general program of development and formation of a University of the European type ensures the successful project fulfillment. The management of such a complex project requires the overall focus of the leaders' powers of three powerful subdivisions: the International ZIMC office, the NUS Educational Scientific Center of International Cooperation and the NUS Shipbuilding Institute.

It should be noted, that there is a high demand in the employers' market in China on the product of this project - the graduates of the shipbuilding industry. So, all the graduates of the first group were employed at the leading enterprises in Shanghai and Zhoushan. The graduation of the second group has been held recently, so there are no current data about their employment at the moment, but the preliminaries give a reason to conclude that these graduates will find a good place in life. 
As the executives of the project the top-class experts in their field of education and project management are selected by the NUS. The responsibility for certain training directions lies upon the department, not upon the particular individuals, because in case of a negative response of the "human factor", the substitution is picked up by the senior executives of the department or another way is found to solve the problem.

The NUS applies successfully the mechanism of the "responsibility distribution" in which the primary responsibility for a positive result lies not only upon the main executive which is the Educational Scientific Center of International Cooperation, but also upon all other structural subdivisions of the University which are involved into the project. Therefore, a synergistic effect is achieved by the joint efforts aimed at the fulfillment of duties of the University.

As part of improving the PME-methodology, universal computing program (UCP) for calculation of a quantitative assessment of the quality of teaching in educational establishment has been developed on the basis of mathematical model that is defined by the dispersion of average score and calculated as the weighted arithmetic mean of score dispersion for each discipline, with quantitative measure calculated as the return value to the quadratic coefficient of variation.

For a quantitative assessment of the quality of teaching is taken adjusted average score, that students have received as a result of the final control on discipline that is taught by concrete teachers in the semester.

Average score that students have received as a result of final control in all disciplines of kteacher, calculated as an average weighted from average scores in each discipline as follows:

$$
\bar{X}_{k}=\frac{\sum_{1}^{m} X_{j} \times f_{j}}{\sum_{1}^{m} f_{j}}
$$

Where $\mathrm{Xj}$ - average score that students received from k-teacher of the $\mathrm{j}$-discipline in the observed period;

$\mathrm{fj}$ - the amount of $\mathrm{j}$-discipline credits in the observed period;

$\mathrm{m}$ - number of disciplines.

Spread of students' scores is taken into account by dispersion of average score, earned by students as a result of final control in all disciplines of k-teacher. Dispersion is calculated as weighted arithmetic mean of the scores dispersion for each discipline as follows:

$$
\overline{\sigma_{k}^{2}}=\frac{\sum_{1}^{m} \sigma_{j}^{2} \times f_{j}}{\sum_{1}^{m} f_{j}}
$$

Where $\sigma_{j}^{2}$ - dispersion of the scores that have been received by the students of k-teacher in jdiscipline in the observed period, which is calculated using the formula: 
$\sigma_{j}^{2}=\frac{\sum_{1}^{S}\left(X_{j}-X_{l}\right)^{2}}{S}$

Where Xl - score, received by i-student from k-teacher in the j-discipline in the observed period; $\mathrm{S}$ - quantity of students who studied from k-teacher of the j-discipline for the observed period. Relative indicator $\Omega \mathrm{k}$ that quantifies the quality of the k-teacher as a result of the final control of all disciplines is calculated as inverse to the quadratic coefficient of variation:

$$
\Omega_{k}=\frac{\overline{X_{k}}}{\overline{\sigma_{k}}}
$$

Rating score of the quality of work at the University of k-teacher calculated as follows:

$$
R_{k}=\frac{\Omega_{k} \times F_{k}}{\sum_{1}^{n} \Omega_{k} \times F_{k}}
$$

Where Fk - the quantity of credits that was given by k-teacher for the observed period; $\mathrm{n}$ - number of teachers of the institution (or its structural unit) for the observed period.

As a control for the quality of teaching in " $2+2$ " joint educational program the calculations of quantitative assessment of quality of teaching for Chinese students groups have been performed.

As an example the teaching evaluation for 8 semester 2016 is showed. During this period, the students were provided with educational services in 10 disciplines:

$\mathrm{j} 1$ - The theory of the ship and means of development of ocean;

j2 - Technology Basics of Shipbuilding and Sea technique;

j3 - Basics of Economy and Management of Enterprises;

j4 - Design of Ship and Sea technique;

j5 - Labour Protection Basics;

j6 - General Ship Mechanisms and Systems;

j7 - CAD, CAE, CAM systems in shipbuilding;

j8 - Basics of Ship Power Plant automatic Control;

j9 - Russian language;

j10 - English language;

Conducting lectures, practical and laboratory classes on these subjects were provided with a team of teachers from 14 people, as in some disciplines lecture material was provided by one professor, and practical and laboratory classes - other. In this case, a qualitative assessment of teaching is calculated for a particular discipline and is to characterize the team of teachers.

For the quantitative assessment of the quality of teaching was accepted adjusted average score that was received by the students as a result of the final control on discipline.

To significantly reduce the time for calculations, the universal computing program has been created, which allows to process extensive data blocks with the visualization of the results in the two-dimensional coordinate system. This program was implemented to working process of Educational and Scientific Center of International Cooperation of the Admiral Makarov National 
University of Shipbuilding to control the quality of the provision of educational services for international customers.

Common Interface of universal computing program (UCP) for calculation of a quantitative assessment of the quality of teaching in educational establishment is presented in Figure 5.

Scores evaluated by teacher, either by student are filled in the first calculation block field program. The block algorithm allows to make calculation of a group of up to 45 students at a time. After entering scores click "Расчёт" - in the appropriate fields the results of average score, dispersion (standard deviation) relative indicator of quality will be shown. The calculation results also displayed on the first graphical unit for comparing average scores to the scores of the individual student.

For each discipline perform the same operation.

In the second calculation block fill the number of credits for each discipline that are analyzed. The calculation results by teacher evaluation fill to the relative fields of the first block. After pressing "Расчёт рейтинга", the results of teachers ranking are displayed in the Rk fields and in the second graphics unit.

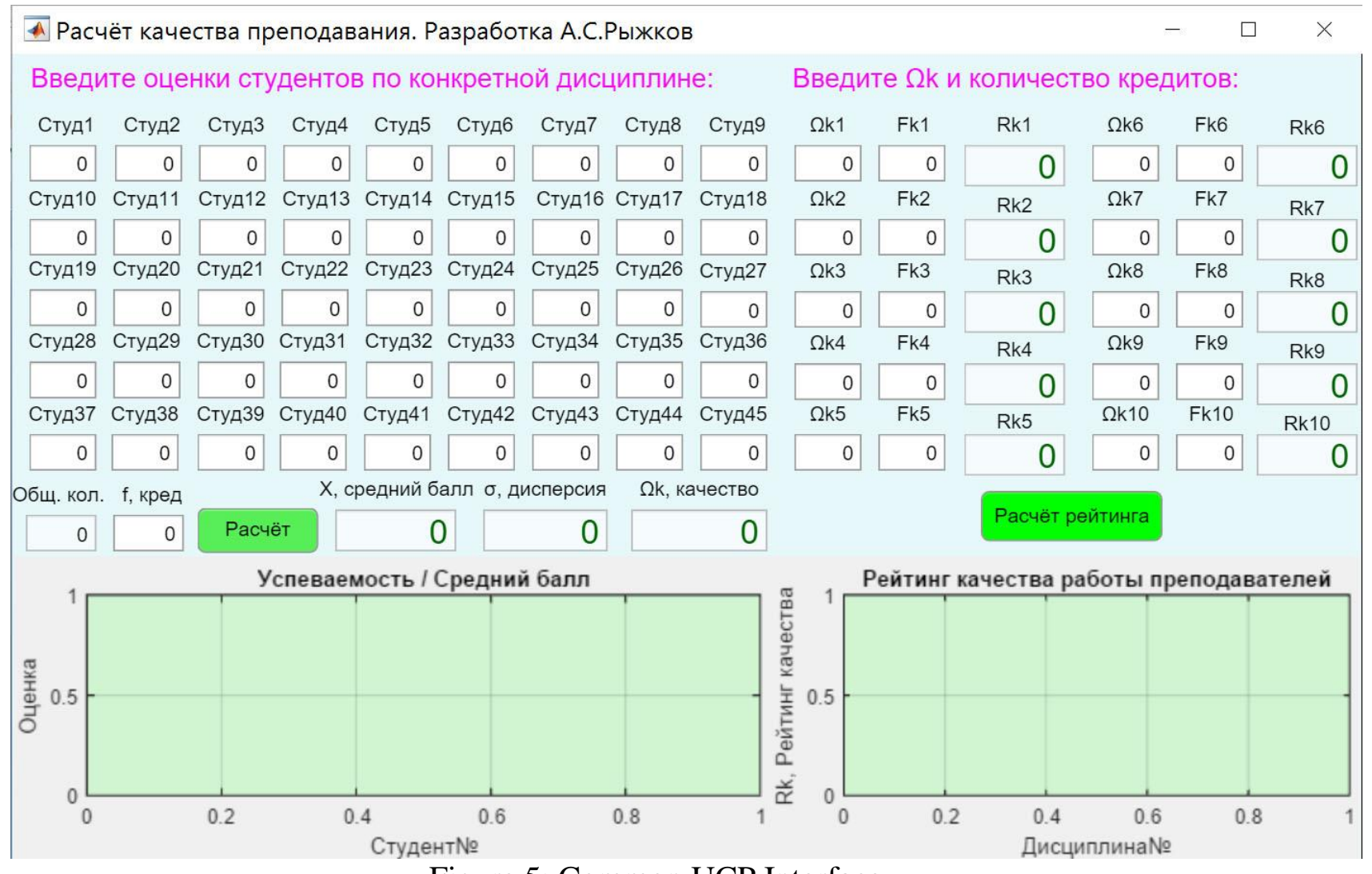

Figure 5: Common UCP Interface.

The results of the calculations are shown in Figure 6 and Table 1. The analysis of the results of the quantitative characteristics of the relative $\Omega \mathrm{k}$ indicator (Figure 7) let us to make an initial 
determination of the quality of teachers in result of the final control in all disciplines. As in the case with the results of the rating score of quality of teachers (Figure 8), the highest quality of educational services rated to discipline $\mathrm{j} 4$ - Design of Ship and Sea technique $(\mathrm{R}=0,192)$, followed by discipline $\mathrm{j} 2$ - Technology Basics of Shipbuilding and Sea technique $(\mathrm{R}=0,139)$ and $\mathrm{j} 1$ - the theory of the ship and means of development of ocean $(\mathrm{R}=0,139)$. Worst rating for j10 discipline - English language $(R=0,51)$, slightly better $\mathrm{j} 9$ - Russian language $(R=0,54)$ and j5 - Labour Protection Basics $(\mathrm{R}=0,56)$.

Recommended the teaching with a rating score of performance $\mathrm{Rk} \geq 0,06$ to consider as that which meets the high standards of education.

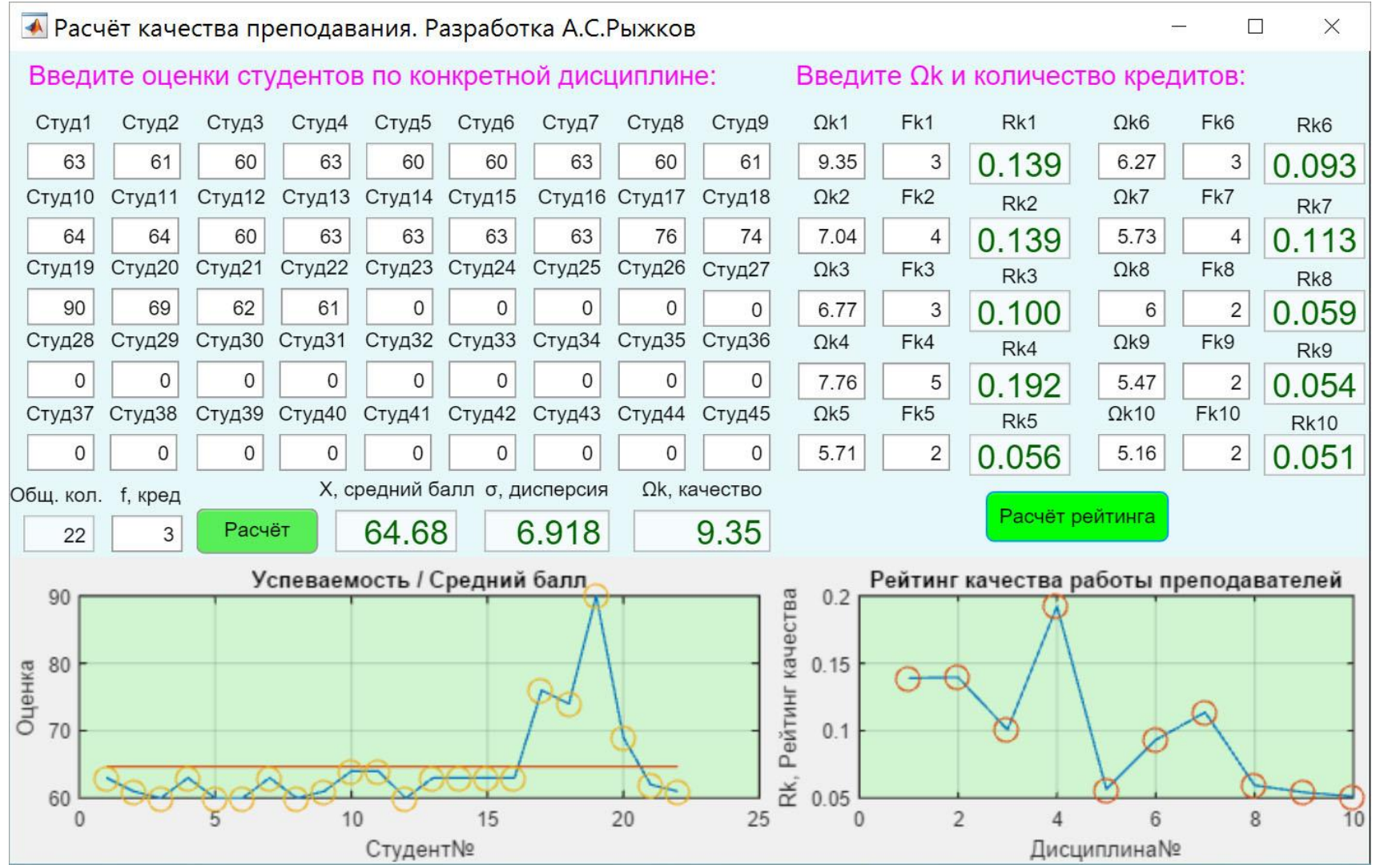

Figure 6: The result of the calculation of the quantitative assessment of the quality of teaching in UCP for 22 students in 8 semester 2016.

Table 1: The result of the calculation of the quantitative assessment of the quality of teaching for 22 students in 8 semester 2016 on joint educational program « $2+2 »$.

\begin{tabular}{l|l|l|l|l|l|l|l|l|l|l|}
\cline { 2 - 12 } & $\mathbf{j 1}$ & $\mathbf{j 2}$ & $\mathbf{j 3}$ & $\mathbf{j 4}$ & $\mathbf{j 5}$ & $\mathbf{j 6}$ & $\mathbf{j 7}$ & $\mathbf{j 8}$ & $\mathbf{j 9}$ & $\mathbf{j 1 0}$ \\
\hline $\boldsymbol{X}_{\boldsymbol{j}}$ & 64,7 & 81,4 & 78,9 & 81 & 79,6 & 71,3 & 81,1 & 71 & 68,7 & 72,9 \\
\hline $\boldsymbol{X}_{\boldsymbol{k}}$ & 64,7 & 81,4 & 78,9 & 81 & 79,6 & 71,3 & 81,1 & 71 & 68,7 & 72,9 \\
\hline $\boldsymbol{f}_{\boldsymbol{i}}$ & 3 & 4 & 3 & 5 & 2 & 3 & 4 & 2 & 2 & 2 \\
\hline $\boldsymbol{F}_{\boldsymbol{k}}$ & 3 & 4 & 3 & 5 & 2 & 3 & 4 & 2 & 2 & 2 \\
\hline$\sigma_{j}^{2}$ & 6,92 & 11,56 & 11,66 & 10,44 & 13,95 & 11,38 & 14,14 & 11,83 & 12,56 & 14,14 \\
\hline
\end{tabular}




\begin{tabular}{l|l|l|l|l|l|l|l|l|l|l|}
\hline$\overline{\sigma_{k}^{2}}$ & 6,92 & 11,56 & 11,66 & 10,44 & 13,95 & 11,38 & 14,14 & 11,83 & 12,56 & 14,14 \\
\hline$\Omega_{k}$ & 9,35 & 7,04 & 6,77 & 7,76 & 5,71 & 6,27 & 5,73 & 6 & 5,47 & 5,16 \\
\hline $\boldsymbol{R}_{\boldsymbol{k}}$ & 0,139 & 0,139 & 0,100 & 0,192 & 0,056 & 0,093 & 0,113 & 0,059 & 0,054 & 0,051 \\
\hline
\end{tabular}
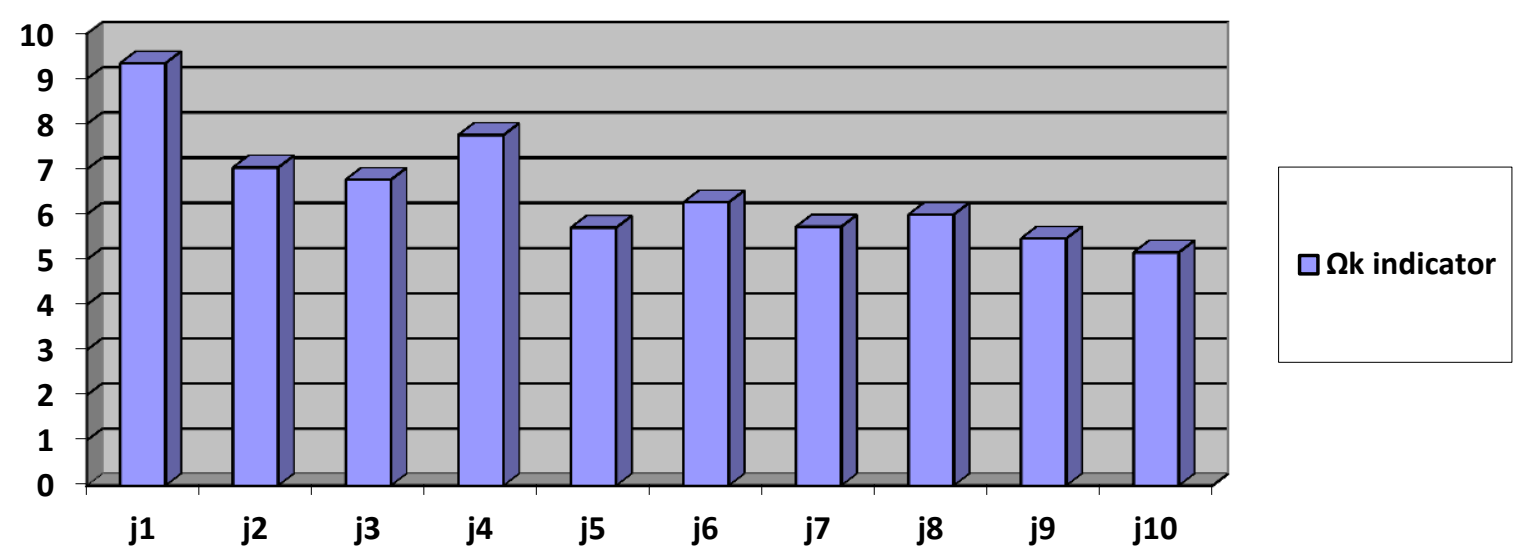

Figure 7: Relative $\Omega \mathrm{k}$ indicator of quantitative characteristics of quality of teaching of 10 disciplines for 8 semester 2016 on joint educational program « $2+2 »$.
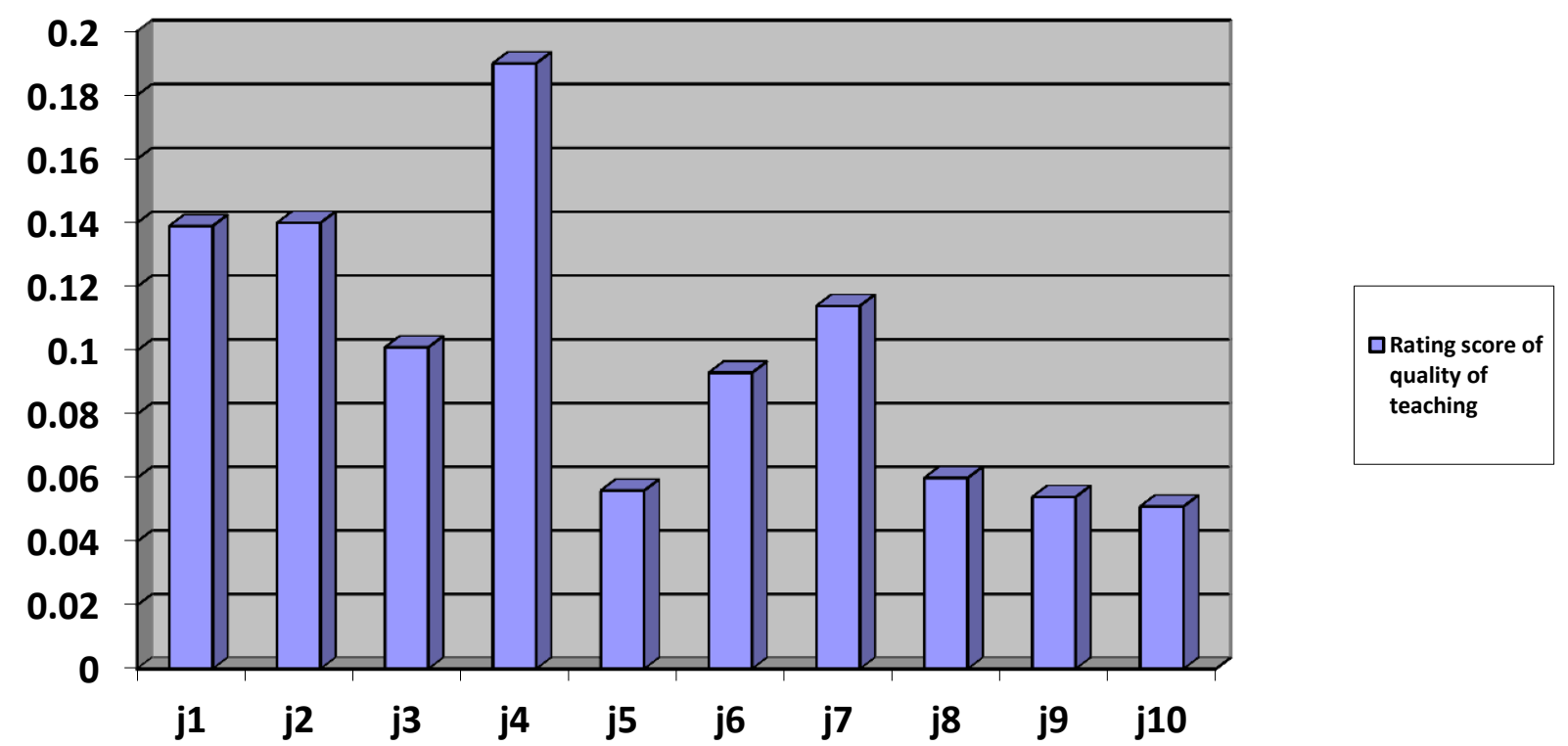

Figure 8: Rating score of quality of teaching of 10 disciplines for 8 semester 2016 on joint educational program $\ll 2+2 »$.

\section{Conclusion}

Based on the results of the project management performed by Educational Scientific Centre of International Cooperation of NUS the project management methodology to provide the 
educational services to the foreign customer has been developed (Project Management for Education, PME).

This methodology allows to effectively manage international educational projects, which is confirmed by its application in a successful implementation of a number of international contracts of NUS.

In order to develop the project management methodology to provide the educational services to the foreign customer was created a working version of a universal computing program (UCP) based on method of calculation of a quantitative assessment of the quality of teaching. UCP can handle large blocks of data with visualization of a results in a two-dimensional coordinate system.

The use of UCP leads to a significant reduction in time spent of executors of international contracts to meet the challenges of quality management educational services provision.

As a control for the quality of teaching in " $2+2$ " joint educational program the calculations of quantitative assessment of quality of teaching for Chinese students groups have been performed. The obtained results make it possible to perform unprejudiced monitoring of the work of teachers with foreigners. During an interview on the results of the calculations was revealed shortcomings in the work on the above subjects. It adopted a package of measures to eliminate them and improve the quality of educational services for international customers.

These calculations confirm the effectiveness of the proposed PME methodology.

\section{References}

[1] Bobrytska V.I. "Mobility as a key principle of forming a European educational space" / European integration of higher education in Ukraine in the context of the Bologna Process number 3 (Annex 2): theoretical and scientific-methodical journal "Higher Education in Ukraine", publisher Institute of Higher Education NAPS of Ukraine, Kyiv, 2013, p. 234 - 238;

[2] Focus on Higher Education in Europe: The Impact of the Bologna Process / European Commission- URL: http://www.Eurydice.org;

[3] The Bologna Process 2020 - The European, Higher Education Area in the new decade. Communiquй of the Conference of European Ministers Responsible for Higher Education. Leuven and Louvain-Ia-Neuve, 28-29 April 2009. - URL: http:// www.bologna2009benelux.org;

[4] Calculated based on the data from UNDP, 'Human Development Report 2013. The Rise of the South: Human Progress in a Diverse World', New York, 2013

[5] Belikov S.B., Klimov O.V., Pavlenko D.V., Tkach D.V. "Regional labor market - a factor that determines the training of young specialists" / European integration of higher education in Ukraine in the context of the Bologna Process number 3 (Annex 2): theoretical and methodical journal "higher education in Ukraine", publisher Institute of higher education NAPS of Ukraine Kyiv, 2013, p. $113-116$.

[6] A. Ryzhkov "Management of international educational projects of National University of Shipbuilding on the example of Ukrainian-Chinese cooperation" / Zbirnik Naukovih Prats NUS number 6, 2014, c. Mykolaiv, Art. 84 - 91.

[7] Matthew Guay «Project Management 101: The Complete Guide to Agile, Kanban, Scrum and Beyond»/ URL: https://zapier.com 
[8] Karen E Papke-Shields, Kathleen M. «Boyer-WrightStrategic planning characteristics applied to project management» / International Journal of Project Management. Volume 35, Issue 2, February 2017, Pages 169-179. URL: https://www.journals.elsevier.com

[9] Guidelines for Project Management: Transl. from English. / Under. Ed. SD Bushuev. - 2nd ed., Revised. - K .: Publishing house "Business Ukraine", 2000. - 196 p.

[10] Burkov N.V., Novikov D.A. "Models and Mechanisms theory of active quality management systems in the preparation of professionals." - M .: Research Center of quality control specialists preparation, 1998.

[11] Zynnurov U.H., Huzayrov M.B. "Comments expenses for the preparation of professionals in dependence from qualification requirements for graduate" / - M .: ITs, 1991.

[12] Hotomlyanskyy O., Derevyanko T. "Building Balanced Scorecard" // Universities and Education Management. - 2005. - Vol.8. - №2. - with. 49 - 53.

[13] Hotomlyanskyy O., Derevyanko T., "Methodological issues of professional evaluation results of the teaching staff of higher education" // Education and Management. - 2006 - Vol.9. - № 3-4. with. $145-151$.

[14] Balyhin G.A. "Management education development, organizational-economic aspect." // M .: Economics, 2003. - 428 p.

[15] Ryzhkov A.S. "Quality Management Education NUS program "2+2" with ZIMC" // Nikolaev, 2017. collections of the Scientific works NUS №1, 2017.

[16] Ryzhkov A.S. "Quality Management Education NUS program "3+X" with ZIMC" // Nikolaev, 2017. The International collections of the Scientific works NUS №1, 2017.

[17] A. Ryzhkov "Development of a methodology to provide educational services to the foreign customer project management" // Nikolaev, 2016 NUS Journal

[18] Ryzhkov S.S. "Report of the rector for 5 years" / NUS Publishing, 2013.

\footnotetext{
*Corresponding author.

E-mail address: oleksandr.ryzhkov@ nuos.edu.ua

Web address: http://idept.nuos.edu.ua
} 